\title{
Mothers' Attitudes Regarding Parental Styles and Child Abuse in Croatia
}

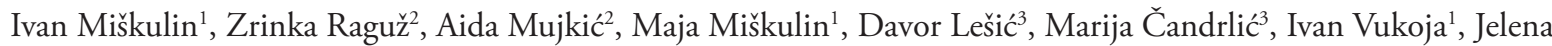 \\ Kovačević ${ }^{1}$, Slavko Čandrlić ${ }^{3}$, Hrvoje Palenkić ${ }^{1}$ \\ ${ }^{1}$ Josip Juraj Strossmayer University of Osijek, Faculty of Medicine Osijek, Osijek, Croatia, ${ }^{2}$ University of Zagreb, School of \\ Medicine - Andrija Stampar School of Public Health, Zagreb, Croatia, ${ }^{3}$ Josip Juraj Strossmayer University of Osijek, Faculty of \\ Dental Medicine and Health Osijek, Osijek, Croatia
}

Correspondence: dr.kovacevic.jelena@gmail.com; Tel.: + 385996041 707; Fax.: + 38532300500

Received: February 10, 2021; Accepted: June 12, 2021

\begin{abstract}
Objective - To explore Croatian primipara mothers' attitudes toward strict-authoritarian parenting style and to analyze if there are any maternal factors, more specifically age, education and place of residence that could be linked to mothers' attitudes toward different statements reflecting abusive behavior toward children and statements reflecting safety behavior toward children. Materials and Methods - A cross-sectional study was carried out at the maternity ward of the Clinical Hospital Center Zagreb, Clinic for Women's Diseases and Obstetrics in Zagreb, Croatia. A specially designed anonymous questionnaire served as a research tool for this study that included 284 Croatian primipara mothers. Results - This study showed that younger age, lower level of education and residence of mothers in less urbanized areas are related to more positive attitudes toward authoritarian parenting style and abusive behavior. Conclusion - The aforementioned group of mothers is one of the priority groups for conducting primary intervention for preventing child abuse. In this sense, primary prevention should be carried out with future parents before they have their own children so that they can understand the problem, gain the necessary knowledge, accept attitudes that disapprove of child abuse and behave in this way in their lives. The economic, social and moral support of the whole society is a significant factor in this matter.
\end{abstract}

Key Words: Mothers • Attitudes • Parenting Styles • Child Abuse • Prevention of Child Abuse.

\section{Introduction}

The problem of child abuse and child neglect is embedded into foundations and values of modern society. Numerous actors in the society are continually working on the reduction of child abuse and child neglect, nevertheless, we often witness reports on extreme cases of child abuse where children become victims of parents, relatives, friends or strangers (1).

According to Center for disease control and prevention (CDC), child abuse is any act or lack of action of a parent or a guardian that results in damage, potential damage or hazard for the child (2, $3)$. Consequences of child abuse are numerous and complex. Direct consequences of child abuse may include death of a child, physical injuries in different forms: bruises, skin lacerations, burns, bone fractures, brain hemorrhage, brain contusions etc., emotional consequences such as feeling unloved, rejected, damaged relationship with the guardians, fear, anxiety, dissociation, insecurity, shame, guilt, low self-esteem, etc. (4). Children suffering abuse have health burdens. Recent research indicates that chronic degenerative diseases such as hypertension, diabetes type 2 , ischemic heart disease, chronic lung disease, irritable bowel syndrome and malignant tumors may be connected to abuse during childhood. As possible explanation, it is suggested that persons that experienced abuse during childhood more often develop habits and life-styles associated 
with higher risks, such as smoking, unhealthy diet and alcohol abuse (5), but also damages to the immune system as a direct consequence of abuse can have effects on health many years after the abuse had happened. Psychiatric problems are also more often, such as depression, anxiety, suicide attempts, drug abuse, aggression and cognitive impairments $(6,7)$. Social health of a child is also affected by the abuse. Consequences of child abuse affect the whole family and society. Social and economic consequences of child abuse affect community directly through different forms of antisocial, delinquent, and criminal behavior of an abused child, leading to medical cost of different educational and social institutions. Long-term effects of child abuse are associated with the loss of productivity, quality of life and early death of abused victims (6).

There are four different parenting styles: permissive, authoritarian, authoritative and neglecting style $(8-10)$. In a permissive parenting style, a parent has little demands toward a child and gives it a great freedom. Permissive parent accepts a child's wishes and actions without punishment. Authoritarian parenting style is characterized by great demands and surveillance over a child while trying to form a child according to certain rules. Authoritarian parents show little love and affection. Authoritative parenting style sets boundaries and ensures surveillance, but also shows affection, understanding and creates a dialog with a child (8 - 10). Children of permissive parents have high self-esteem, problematic behavior and low school achievement. Children of authoritarian parents have average school achievement, but are less socially competent, they have low self-esteem and more often suffer from depression compared to children of permissive parents (11). Children of authoritative parents have better school achievements, better social behavior and personal satisfaction. Children of neglecting parents have lowest achievements in every area (12). These children can have cognitive and social impairments, as well as lack of empathy for others (13). Generally, authoritative parenting style is considered protective and leads to the best outcomes for children $(14,15)$. Authoritarian and permissive parenting styles are considered dysfunctional (15). Studies showed that authoritarian parenting style was related to parent-child aggression and child abuse potential $(15,16)$. Supportive and authoritative parents were negatively associated with children victimization (17). Authoritative parenting was associated with lower risk of all types of child abuse (15). Parenting styles, both positive and negative, are transferred over generations (18). However, most of the parents who were victims of child abuse do not abuse their children, which shows that intergenerational transfer of abuse can be terminated (19).

In the light of current knowledge, the aims of the study were to determine the attitudes of mothers of firstborn children toward the authoritarian parenting style; to determine mothers' attitudes towards different claims related to child abuse and neglect; to determine mothers' attitude toward claims related to safety behavior and secure up-bringing of children; and to analyze how age, education level and place of residence affect mothers' attitudes.

\section{Methods}

This cross-sectional study was conducted in the period from April to December of 2008 at the maternity ward of Clinical Hospital Centre Zagreb, Clinic for women's diseases and obstetrics, Zagreb, Croatia. In this period, there were 370 mothers with their first childbirth. Of those, 284 agreed to participate in the study. Therefore, the response rate was $76.8 \%(284 / 370)$.

\section{Participants}

The participants in the study were mothers of firstborn children who were asked to participate in the study during the first three days at the maternity ward. Two students of the $6^{\text {th }}$ year of medicine approached the mothers, informed them about the study, gave them the questionnaire, and collected the filled-out questionnaires afterwards. All participants signed an informed consent. The study was approved by the Ethical Committee of the School of Medicine at University in Zagreb. 


\section{Questionnaire}

Questionnaire used in this study comprised 40 questions aiming to determine knowledge, attitudes, and behavior of parents of preschool children in order to prevent accidents and to increase child safety of preschool children. The research was conducted as a part of the project of the Ministry of Science, education and sports "Prevention of accidents and increase of child safety in preschool children" (108-1081871-1895). For the purpose of this study, only 12 out of 40 questions that were related to the investigated attitudes of mothers of firstborn children were analyzed. Questions are listed in Table 1 in the Results section.

\section{Statistical Analyses}

Distribution of frequencies of investigated variables was described using descriptive statistics. All variables were tested for normality of distribution using Shapiro-Wilkinson's test. Since the sample was not distributed normally, differences between the groups were determined by using Mann-Whitney $\mathrm{U}$ test. Statistical difference was set at $\mathrm{P}<0.05$.
Statistical software SPSS for Windows, version 13.0 was used (SPSS Inc., Chicago, IL, USA).

\section{Results}

According to age, the participants were divided into 3 groups: young (17 to 24 years) with $29.8 \%$ of the participants, middle aged ( 25 to 29 years) with $37.9 \%$ of the participants and older group (30 and more years) with $32.3 \%$ of the participants. According to education level, the participants were divided into groups according to the highest completed education: primary $(1.4 \%$ of the participants), secondary (54.3\% of the participants) and university education ( $44.3 \%$ of the participants). According to the place of residence, $79.1 \%$ of the participants were from the capital city of Zagreb and its suburbia and they were categorized as a highly urban group. All other participants were categorized as less urban since they were from smaller towns and villages gravitating to the city of Zagreb.

Table 1 shows attitudes of mothers toward authoritarian parenting style according to different claims regarding child abuse and neglect, and claims regarding safety behavior and secure upbringing.

\section{Table 1. Attitudes of Mothers of Firstborns toward of Parenting Style and Child Abuse}

\begin{tabular}{|c|c|c|c|c|}
\hline \multirow{2}{*}{ Statement } & \multirow{2}{*}{$\mathrm{N}^{*}$} & \multicolumn{3}{|c|}{ Mothers' attitudes; N (\%) } \\
\hline & & Agree & Indecisive & Disagree \\
\hline A parent always has to be strict and authoritative & 278 & $51(18.3)$ & $85(30.6)$ & $142(51.1)$ \\
\hline It is enough to educate one parent regarding child safety & 279 & $6(2.1)$ & $5(1.8)$ & $268(96.1)$ \\
\hline Avoiding obligate vaccination is a form of child neglect & 280 & $247(88.2)$ & $23(8.2)$ & $10(3.6)$ \\
\hline Older child in the family should take care for the younger one. & 280 & $42(15.0)$ & $86(30.7)$ & $152(54.3)$ \\
\hline A parent can slap a child if he has no other choice & 280 & $14(5.0)$ & $48(17.1)$ & $218(77.9)$ \\
\hline An educator/teacher (in a kindergarten/school) can hit a child in order to discipline it & 278 & $8(2.9)$ & $16(5.8)$ & $254(91.3)$ \\
\hline $\begin{array}{l}\text { If a preschool child is behaving badly while guests are visiting, it needs to be locked in } \\
\text { another room until guests leav }\end{array}$ & 279 & $3(1.1)$ & $5(1.8)$ & $271(97.1)$ \\
\hline Some children can only be raised by physical punishment & 280 & $4(1.4)$ & $14(5.0)$ & $262(93.6)$ \\
\hline If an infant does not stop crying, shaking it can help & 278 & $7(2.5)$ & $25(9.0)$ & $246(88.5)$ \\
\hline $\begin{array}{l}\text { Children fighting in a kindergarten should not be stopped as they are preparing for life that } \\
\text { way }\end{array}$ & 280 & $1(0.4)$ & $25(8.9)$ & $254(90.7)$ \\
\hline Small amounts of alcohol are not harmful for a preschool child & 278 & $1(0.4)$ & $5(1.8)$ & $272(97.8)$ \\
\hline $\begin{array}{l}\text { Weapon in a family is not dangerous for a preschool child because it does not know how and } \\
\text { is not able to operate with it }\end{array}$ & 279 & $7(2.5)$ & $2(0.7)$ & $270(96.8)$ \\
\hline
\end{tabular}

N Number of mothers that answered. 
Comparison between the groups according to age showed that middle-aged mothers were more permissive in their parenting $(\mathrm{P}=0.036)$. Comparing young and older mothers showed that older mothers were more permissive $(\mathrm{P}=0.003)$, while young mothers were more strict in parenting. There were no differences between middle-aged

mothers and older ones $(\mathrm{P}=0.162)$. When considering education level, mothers with primary and secondary education had similar attitudes toward children upbringing $(\mathrm{P}=0.237)$. Mothers with university education reported a more permissive parenting style $(\mathrm{P}=0.001)$. Mothers from highly urbanized areas such as the city of Zagreb and its suburbia were less strict in parenting than mothers from less urbanized areas $(\mathrm{P}=0.032)$.

\section{Discussion}

The study showed that mothers' age, education level and place of residence are associated with different attitudes toward parenting styles and child safety measures. Younger mothers expressed more positive attitudes toward authoritarian parenting. Similar to this study, other research showed that lower maternal age predicted harsher and less supportive parenting (20). Although older mothers usually have higher education and higher income (21), even after accounting for other socioeconomic factors, mothers' older age was positively associated with warmth and sensitivity towards children (22). However, there are studies that found no differences in positive-interaction parenting between mothers of a different age (20).

Other studies found higher education levels of mothers to be associated with positive-interaction parenting as they have a better understanding of the influence of parenting on social and cognitive development of children (20). Similarly, mothers with university education in this study showed less positive attitudes toward authoritarian parenting.

Previous research is inconsistent with regard to place of residence and parenting styles (23). Further research of these associations is required since they are not numerous and the matter is complex, i.e. one study found that rural communities preferred authoritarian parenting style for male children and authoritative parenting style for female children, while on the other hand, urban communities had predominant authoritarian parenting style for female children (24).

Harsh parenting is often considered condition precedent to child maltreatment and is in focus of critical prevention and intervention (15). The first step in the prevention and management of child abuse is to define a problem and to determine the risk factors, create strategies of prevention and at last to ensure the implementation of those strategies (25). Initiatives should focus on preparations for family life and parenting, assisting families with guidance and support, informing the community through media and increasing child protection with consistent implementation of laws (12).

Preparations for family life and parenting include education of youth before starting a family, education of parents and guardians about family life and parenting challenges, education on problem solving and approach to different parenting situations. Assistance to families with guidance and support can be given in house calls, when child development can also be monitored, while in the same time parents can be advised and supported (26). The public is not aware of tragic consequences of improper upbringing. Prevention campaigns and education can reach the public through media, but also through regular institutional education. Until now, only 22 out of 47 European Council member states have legally forbidden physical punishment of children (27), although physical maltreatment behaviors were associated with child abuse potential (16). In order to implement the laws and to punish those who brake it, there has to be a system of reporting crimes, and also a public awareness on the need to report child abuse. However, this study showed that only $77.5 \%$ of mothers would report to the authorities their suspicion about any child abuse, showing that public opinion in Croatia is still not at the appropriate level. In cases where primary prevention has failed, it is important to discover child abuse as early as possible and to help 
the child and the whole family. Healthcare workers have significant role in this process. This study showed that young mothers with low education from less urbanized areas are the priority group for primary prevention measures in order to prevent child abuse.

The study has several limitations that need to be addressed. The study had a relatively small sample of mothers with firstborns so obtained results can not be interpreted as the reflection of attitudes of all mothers in Croatia. Secondly, a high share of mothers from Zagreb and its suburbia and low share of mothers from less urbanized areas of Croatia also restricts results from being generalized to all Croatian mothers, and indicates that results regarding the place of residence should be interpreted with caution.

\section{Conclusion}

The study showed that in the Republic of Croatia younger age, lower education level and place of residence in less urbanized areas are associated with higher incidence of answers that reflect authoritarian parenting style and abusive behavior. Hence, this group of mothers is one of the priority groups for introduction of primary prevention in order to prevent child abuse. Primary prevention should be conducted with future parents before they have children of their own in order for them to understand the problem, obtain appropriate knowledge, accept attitudes that disapprove of child abuse and to behave in this manner. Economic, social and moral support of the whole society play an important factor.

Conflict of Interest: The authors declare that they have no conflict of interest.

Authors' Contributions: Conception and design: ZR, AM and IM; Acquisition, analysis and interpretation of data: IM, ZR, AM, MM, JK and DL; Drafting the article: IM, ZR, AM and MM; Revising it critically for important intellectual content: JK, DL, MČ, HP, IV and SČ; Approved final version of the manuscript: IM, ZR, AM, MM, DL, MČ, IV, JK, SČ and HP.

\section{References}

1. Velki T, Bošnjak M. Association of parenting educational conduct with physical punishment of children (in Croatian). Life and school. 2012;58:63-82.

2. Mujkić A. Accident prevention and preschool child safety improvement: a handbook (in Croatian). Zagreb: UNICEF Office for Croatia; 2010.

3. Leeb RT, Paulozzi L, Melanson C, Simon T, Arias I. Child maltreatment surveillance: uniform definitions for public health and recommended data elements. Atlanta, GA: Centers for Disease Control and Prevention, National Center for Injury Prevention and Control; 2008.

4. Pinheiro PS. World report on violence against children. Geneva: United Nations; 2006.

5. Felitti VJ, Anda RF, Nordenberg D, Williamson DF, Spitz AM; Edwards V, et al. Relationship of childhood abuse and household dysfunction to many of the leading causes of deaths in adults. Am J Prev Med. 1998;14:245-58.

6. Runyan D, Wattam C, Ikeda R, Hassan F, Ramino L. Child abuse and neglect by parents and other caregivers. In: Krug E, Dahlberg LL, Mercy JA, Zwi AB, Lozano R, editors. World report on violence and health. Geneva: World Health Organization; 2002.

7. Straus MA, Sugarman DB, Giles-Sims J. Spanking by parents and subsequent antisocial behavior of children. Arch Pediatr Adolesc Med. 1997;151:761-7.

8. Hotelling BA. Styles parenting. J Perinat Educ. 2004;13:42-4.

9. Ljubetić M. Being a competent parent (in Croatian). Zagreb: Mali professor; 2007.

10. Brković I. Why do we want to be parents? Parenting and parental styles (in Croatian). In: Čorkalo Biruški D, editors. Applied psychology: questions and answers. Zagreb: Školska knjiga; 2009.

11. Marsiglia CS, Walczyk JJ, Buboltz WC, Griffith- Ross DA. Impact of parenting styles and locus of control on emerging adults' psychosocial success. J Educ Hum Devel. 2007;1:1.

12. Helander EA. Children and violence: The world of the defenseless. New York: Palgrave Macmillan; 2008.

13. Straus MA, Savage SA. Neglectful behavior by parents in the life history of university students in 17 countries and its relation to violence against dating partners. Child Maltreatment. 2005;10:124-35.

14. DeVore ER, Ginsburg KR. The protective effects of good parenting on adolescents. Curr Opin Pediatr. 2005;17(4):460-5. 
15. Lo CKM, Ho FK, Wong RS, Tung KTS, Tso WWY, Ho MSP, et al. Prevalence of child maltreatment and its association with parenting style: a population study in Hong Kong. Int J Environ Res Public Health. 2019;16:1130.

16. Rodriguez CM. Parent-child aggression: association with child abuse potential and parenting styles. Violence Vict. 2010;25(6):728-41.

17. Baldry AC, Farrington DP. Protective factors as moderators of risk factors in adolescence bullying. Soc Psychol Educ. 2005;8:263-84

18. Chung EK, Mathew L, Rothkopf AC, Elo IT, Coyne JC, Culhane JF. Parenting attitudes and infant spanking: the influence of childhood experiences. Pediatrics. 2009;124:278-86.

19. Widom CS, Maxfield MG. An update on the 'Cycle of violence'. National Institute of Justice: Research in Brief; 2001. p. 1-8.

20. Kim THM, Connolly JA, Rotondi M, Tamim H. Characteristics of positive-interaction parenting style among primiparous teenage, optimal age, and advanced age mothers in Canada. BMC Pediatrics. 2018;18:2.

21. Bayrampour H, Heaman M. Comparison of demographic and obstetric characteristics of Canadian primiparous women of advanced maternal age and younger age. J Obstet Gynaecol Can. 2011;33(8):820-9.
22. Bornstein MH, Putnick DL, Suwalsky JTD, Gini M. Maternal chronological age, prenatal and perinatal history, social support and parenting of infants. Child Dev. 2006;77(4):875-92.

23. Zhang J, Zhang Y, Xu F. Urban-rural differences in parenting styles in China. Medicine. 2020;99(23):e20592.

24. Dwairy M, Menshar KE. Parenting style, individuation, and mental health of Egyptian adolescents. J Adolesc. 2006;29(1):103-17.

25. Centres for Disease Control and Prevention. Understanding Child Maltreatment. [homepage on the Internet] Atlanta: Centres for Disease Control and Prevention. 2012 [cited 2012 Jan 25]. Available from: http://www.cdc.gov/ violenceprevention/pdf/CM-FactSheet-a.pdf.

26. Regalado M, Sareen H, Inkelas M, Wissow LS, Halfon N. Parents' discipline of young children: results from the national survey of early childhood health. Pediatrics. 2004;113:1952-8.

27. Council of Europe. Human Rights and Rule of Law. [homepage on the Internet] Strasbourg: Council of Europe; 2012 [cited 2012 Jun 15]. Available from: http:// www.coe.int/t/dg3/children/corporalpunishment/Country\%20Activity\%20 Reports/DefaultProgress_en.asp. 